\title{
An inter-ethnic study of gender differentiation and innovativeness among women entrepreneurs in Malaysia
}

\author{
A. Idris \\ Faculty of Business and Accountancy, \\ University of Malaya, 50603 Kuala Lumpur \\ aida_idris@um.edu my
}

Received February 2010

\begin{abstract}
Researchers have generally established the connection between innovativeness and cultural values. However, in these studies men are typically the majority of respondents. There is also no effort in these studies to treat women as a distinct cultural entity although there is evidence suggesting that social conditioning, particularly in masculine societies, induces gender-differentiated behaviors. This paper addresses these issues via a quantitative study examining the effect of masculinity (Hofstede, 1980) on the innovativeness of Malay and Chinese women entrepreneurs in the Malaysian peninsula. Results strongly suggest that for women entrepreneurs, masculinity should not be treated as a single-construct dimension. Rather it should be split into two sub-constructs: ego orientation and gender differentiation. When the construct of masculinity is divided in this way, path analysis reveals that the Malay sample of women entrepreneurs is more innovative than the Chinese even though the latter has a higher index of ego orientation. This may be explained by the former's lower index of gender differentiation.
\end{abstract}

*To whom all correspondence should be addressed.

\section{Introduction}

In Malaysia, gender and inter-ethnic issues have become increasingly important in nation-building. The heterogeneity of the population requires the government to have a deep understanding of the differences among the various ethnic groups. At the same time, since women comprise approximately half of the population (Malaysia. Department of Statistics, 2008a) their social position also greatly affects the country's political and economic scenario.

The study of women entrepreneurs, in particular, is gaining prominence due to the expanding role that women play in the economy. Although women make up only about $15 \%$ of the total number of employers in the country (Labour Force Survey Report, Malaysia, 2008), they are acknowledged for their contribution in reducing unemployment and poverty, and economic gaps among different levels of the society (Ariffin, 1994; Idris, 2009; Ismail \& Joned, 1999; Ong \& Sieh, 2003). The government's recognition of the importance of support for women entrepreneurs has been evident since the late 1990s with the setting up of the Women Entrepreneurs Fund, with an allocation of RM10 million (Malaysia. Economic Planning Unit, 2000). Various other mechanisms of support for women entrepreneurs have also been established, such as the Women's Institute of Management and the National Association of Women Entrepreneurs of Malaysia, which conduct training programs as well as establish networks for these women.
As argued by De Bruin, Brush and Welter (2007), previous entrepreneurship studies have largely focused on masculine processes and behaviors, with the result that comparisons among samples of women - such as inter-ethnic comparisons - are relatively rare. However, available studies do suggest significant differences, particularly in terms of behavior. For instance, Smith-Hunter and Boyd (2004) find that minority women entrepreneurs in the west often operate in racially-segregated markets to offset disadvantages such as lack of capital. Inman (2000) suggests that the problems occur because minority women usually do not enjoy the same formal support mechanisms which white women do, including access to education and financing.

Local studies on inter-ethnic differences tend to focus on the Malay and Chinese ethnic groups because they comprise respectively around $60 \%$ and $30 \%$ of the Malaysian population (Malaysia. Department of Statistics, 2008a). Many local scholars (Abdullah, 1992; Lrong, 1998; Omar, 2003) contend that Malay and Chinese entrepreneurs have different values which have resulted in certain discrepancies in their behavior. However, these studies are generally observational and thus lack scientific data to support their arguments. They are also not particularly concerned with gender issues in entrepreneurship, despite evidence suggesting that social conditioning induces genderdifferentiated behaviors (Ismail \& Ibrahim, 2008). Given the above contention regarding inter-ethnic differences, the issue of culture and its effect on women's entrepreneurial behavior warrants deeper investigation. 
In this study, innovativeness was chosen to represent entrepreneurial behavior due to its association with business performance (Damanpour, Szabat \& Evan, 1989; Zhao, 2005; Neely et al., 2001). Studies on the effect of culture on innovativeness (Shane, 1993; Thomas \& Mueller, 2000; Yeniyurt \& Townsend, 2003) have mainly used Hofstede's (1980) five cultural dimensions, i.e. individualism, power distance, uncertainty avoidance, time orientation and masculinity. From a gender perspective, masculinity is especially interesting because it is most effective in highlighting women's issues. Hofstede (1998) argues that masculinity is:

... the only one of the five that produces consistently different scores for female and male respondents (more ego for the males), except in very feminine countries; it is the only dimension associated with the values that play a role in the differentiation of gender cultures.

(Hofstede, 1998, p.11).

Hofstede (1980) suggests that a masculine society tends to be ego-oriented, deriving job satisfaction from recognition, advancement and challenge rather than from cooperation and working atmosphere. Additionally, masculine societies are more gender differentiating and likely to have fewer women in the more qualified jobs, and fewer men who are receptive to women leaders (Hofstede, 1998). Previous studies have proposed a positive relationship between masculinity and innovativeness (Shane, 1993; Yeniyurt \& Townsend, 2003); data analysis, however, have shown mixed results. While the study by Shane (1993) demonstrates that the effect is negative, Yeniyurt and Townsend (2003) show that the relationship is contingent upon certain moderating variables. Alas again, these studies were not approached from a gender perspective and hence do not discuss the specific effect of masculinity on women's entrepreneurial innovativeness.

In view of existing gaps in the literature, the current study aimed to achieve these objectives:

1. To determine the extent to which Malay and Chinese women entrepreneurs identify with masculine values as per Hofstede's (1980) scale,

2. To examine their level of innovativeness,

3. To determine whether innovative differences among them (if any) appear to be correlated with the scores obtained in 1 . above, and

4. To assess the relevance of Hofstede's (1980) ideas about masculinity to Malaysian women entrepreneurs.

The study began with a review of relevant literature, then moved on to development of the theoretical framework and hypotheses, and a description of the research methodology. The hypotheses were then tested using path analysis, the results of which guided discussions and conclusions made at the end of the study.

\section{Literature review}

In line with the above research objectives, the following literature review is organized along four inter-related themes: Malay and Chinese values and management styles, the economic performance of Malays and Chinese in Malaysia, the position of women in the two communities, and women entrepreneurs in Malaysia.

\section{Malay and Chinese values and management styles}

Zamani (2002) argues that Malay cultural identity is inevitably associated with Islam but Malay interpretations of its teachings are often confused and inaccurate. Malays are said to be simple and straight-forward, tolerant, loyal, unquestioning and shy, although Islam itself does not advocate unconditional observation of these values. The author cites examples of the Malays' adherence to the notion of sincerity or "ikhlas" and suggests that their undue interpretation of the word - i.e. not asking for any form of remuneration - contributes to their simple nature and lack of ambition. Other rigid (mis)perceptions of certain Islamic concepts such as fate or "takdir", and gratitude or "syukur" are also cited to explain the Malays' passive attitude to life. Some literature on Malay culture (Mohamad, 1981; Karim, 1990) further suggests that Malays are an emotional race and plagued by outbursts of tantrum, arguably the polar opposite to the Chinese who are typically considered practical and pragmatic.

While Malay values accentuate obedience and a strict allegiance to Islam, the Chinese are regarded as more open and free-spirited. Purcell (1948) says that Chinese have a very liberal attitude towards many aspects of life such as food, clothing and religion. In addition, studies have also associated the following characteristics with the Chinese: risk-taking and thrifty (Chee, 1986; Syed Azizi, Saufi \& Chong, 2003), adaptable (Maniam, 1986), ambitious, pragmatic, materialistic and driven by meritocracy (Abdullah, 1992).

Some of these attributes appear to be in direct contradiction with the more traditional Confucian values prevalent in Chinese-majority countries such as mainland China, Taiwan and Hong Kong. According to Ying (2000), the common values in these societies include a strict sense of propriety or morality, veneration for tradition and the elderly, not being guided by profit, and contentment with the present. A study by Pan and Zhang (2003) suggests that Chinese in the People's Republic of China are risk-averse. Differences between traditional Confucian values and those observed among Malaysian Chinese have been attributed by some scholars to the immigrant history of the Chinese in Southeast Asia (Syed Azizi et al., 2003; Kuah-Pierce, 2003). The hardship they experienced as immigrants and minority groups are believed to have reshaped their value orientation towards becoming more venturesome, money-driven and adaptable to their new surroundings.

Concerning management styles, Abdullah (1992; 1996) asserts that inter-ethnic differences exist with regards to goal-setting and reward systems. Malays are said to equate success with good interpersonal relationships and communal 
wellbeing, and stress these as business goals. Chinese, on the other hand, place a higher importance on material success. According to Syed Aziz et al. (2003), Chinese appreciate financial incentives more because they view them as appropriate returns to their hard work and commitment. The Chinese' emphasis on wealth-building should not lead to the conclusion that Chinese managers underestimate the value of interpersonal relationships. On the contrary, studies show that the concept of "guanxi" or networking is essential to Chinese organizations (Nonini, 1997). However, while Malays build relationships to maintain harmony and avoid conflict (Zamani, 2002), the Chinese treat them as opportunities for business growth (Nonini, 1997). Due to a high incidence of family business in the Chinese society, most Chinese managers are paternalistic and controlling (Yeung, 1997). They also look upon business ventures as battles and wars which must be won through the survival of the fittest, a principle in line with Sun Tzu's The Art of War (Syed Azizi et al., 2003).

In contrast, Malay managers are widely associated with Islamic management concepts such as "syura" (mediation and consultation), "khalifah" (a wholesome view towards leadership) and "adil" (justice). Muslim managers are not only responsible for the material success of the organization but also for the spiritual well-being of their subordinates (Al-Buraey, 1990; Din, 1999). The concepts of "syura" and "khalifah" thus may explain why it is quite common for Malay managers to take interest in employees' religious practice, for instance by encouraging their subordinates to pray and fast. The Chinese style of paternalism cannot be equated with these concepts of "syura" and "khalifah" for the following reason: the former stems from the Chinese concern for financial success (Yeung, 1997) whereas the latter are aimed at nurturing Muslims' relationship with God.

\section{Economic performance of Malays and Chinese in Malaysia}

Statistics on industry participation (Malaysia. Department of Statistics, 2008b) indicate that the largest discrepancies between the two ethnic groups exist in three industries: Wholesale/retail and repair services, public administration/defense and social security, and agriculture/hunting/ forestry.

Malays predominate in public administration and agriculture-related industries while the Chinese are more involved in trading and commercial activities. The Chinese dominance of trading and commerce appears to be reflected in higher household income (Ninth Malaysia Plan, 2005). These findings reinforce the arguments put forward by earlier researchers such as Lrong (1998) and Omar (2003) on Malay-Sino differences. In particular the Chinese connection with enterprise, risk-taking and wealth-building supports the oft-asserted association between them and masculinity.
The position of Malay and Chinese women in Malaysia

The distribution of Malay and Chinese women with no formal education, as well as those with primary, secondary and tertiary qualifications, is quite similar (Malaysia. Department of Statistics, 2008b). However there are large contrasts between men and women within the same ethnic group. For example while $4,5 \%$ of Malay women have no formal education, only 2,0\% of Malay men fall into the same category. At the other end of the scale, $25.0 \%$ of Malay women have received tertiary education while only $16.8 \%$ of Malay men pursue their education beyond secondary school. Likewise, there are more Chinese women with no formal education than Chinese men. However, this contrasts with the situation at the other end of the educational spectrum where $26.0 \%$ of Chinese women receive tertiary education compared to only $18.1 \%$ of Chinese men.

These figures suggest that both Malay and Chinese women suffer some level of discrimination from their own family in their childhood. For instance, in hard times when a family cannot afford to send all its children to school, more often than not it may be the girls who will have to make the sacrifice. However, the statistics also suggest that the situation is reversed at higher levels of education where a lower percentage of girls than boys in both communities have had to quit after primary school. A possible explanation for this is offered by social conditioning theory (Olsson, 2000; Rigg \& Sparrow, 1994; Watson \& Newby, 2005; Ismail \& Ibrahim, 2008). That is, because men are generally expected to be breadwinners, they are motivated to start working earlier than women. Alternatively, women may be relying on higher education to improve their social standing and are therefore willing to spend greater time and effort attaining it.

Another measure of women's development potential is their rate of employment. Official data show that the percentages of Malay and Chinese women in highly qualified jobs, i.e. professional and semi-professional, are almost equal (approximately 30\%). At the bottom end, however, there is a somewhat clearer distinction between the two groups; only $37,7 \%$ of Chinese women occupy the three low-skilled categories compared to $40,5 \%$ of Malay women (Malaysia. Department of Statistics, 2008b). While more Malay women work as production operators, Chinese women are predominantly found in the service/sales and clerical jobs. Additionally a higher proportion of Malay women than Chinese women are in the agriculture/fishing industry. Comparing women's occupations with those of men reveals a more interesting pattern. The percentage of Malay men who occupy the professional and semi-professional categories is lower than that of the Malay women by around $3 \%$ while the figure for Chinese men exceeds that for Chinese women by more than $7 \%$. In the low-skilled categories, the percentage of Chinese men is less than that of Chinese women by $18.4 \%$ while the percentage of Malay men is less than Malay women by only $6,4 \%$.

These figures suggest that while Chinese women enjoy a slightly better employment status at lower levels compared 
to Malay women - perhaps due to the education factor Malay women occupy a better social position within their own community. In other words, the Malay community seems to provide more room for its women's development compared to the Chinese. From the perspective of Hofstede's (1980) framework, these findings suggest that Chinese people may be more masculine than Malays, thus supporting the propositions made by Lrong (1998) and Omar (2003).

\section{Women entrepreneurs in Malaysia}

Out of 1.87 million female business owners in Malaysia, more than $80 \%$ are in the micro and small business category (Malaysia. Department of Statistics, 2008). Other established characteristics include high involvement in service industries, high usage of personal funding and low rate of market expansion (Lang \& Sieh, 1994; Ong \& Sieh, 2003). Their main motive for going into business appears to be intrinsic, such as self-satisfaction and interest in business (Abdul Rashid, 1992; Ismail \& Joned, 1999; Sieh et al., 1991). They also often face a lot more challenges than men during the start-up stages of their business (Abdul Rashid, 1992). These challenges - such as difficulty in obtaining credit, lack of respect and lack of skilled labour force - may indicate the lesser credibility that women entrepreneurs possess compared to their male counterparts as a result of social prejudice. The above rough profile seems to be consistent with those sketched of women entrepreneurs in many other parts of the world (Brush, 2006; Gundry, BenYoseph \& Posig, 2002; Hisrich \& Ozturk, 1999).

Ndubisi and Kahraman (2005) find that although a majority of Malaysian women entrepreneurs have tertiary qualifications, only a fraction can be found in traditionally male-dominated areas such as transportation and communication. Their study shows that local women entrepreneurs do not engage actively in innovative practices due to the typical characteristics of their business, namely small size, low capital and high service orientation. However, in a study by Idris (2009), there is evidence that innovation is gaining significance among Malaysian women entrepreneurs. According to the author, women perceive certain types of innovation, such as improving packaging, primarily as a way to add value for customers. Others, such as adopting a flexible work schedule, help them cope better with family commitments. The above findings suggest that further research on the subject is timely, and should be able to contribute to greater understanding of gender and entrepreneurship.

\section{Theoretical framework and hypotheses}

In Hofstede's work (1980), masculinity is measured using ego orientation, i.e. the extent to which a society is concerned with self-accomplishment as opposed to social development. However, Hofstede (1980) later deduces a positive correlation between ego orientation and gender differentiation, i.e. the extent to which a society differentiates between male and female social roles and status. Therefore, he treats masculinity as a two-factor concept although in fact only ego orientation is explicitly measured. This is not considered a problem in studies where there is no intention to examine women as a specific sample because role or value conflict within the female person is not likely to be an issue. In this study, however, in which conflicting values within the female person are of considerable interest it is considered more appropriate to measure both factors explicitly. Let us consider the following rationale.

Masculinity has often been linked with innovativeness. Yeniyurt and Townsend (2003) posit that as masculinity indicates the degree to which a society values material success, having the latest and most novel possessions is likely to be important because they symbolize wealth. Thus masculine societies are believed to be more innovative than feminine ones. Shane (1993), and Thomas and Mueller (2000) argue that since masculine traits such as competitiveness and career-orientation are also essential ingredients in the innovative process, individuals or societies with a high masculine index will tend to be more innovative. According to Hofstede (1998), this high inclination towards material success is also positively related with gender role differentiation. In other words, a highly masculine society will score high on both factors. Therefore, a highly innovative society is expected to score high in both ego orientation and gender differentiation.

For a man, of course, this proposition is quite acceptable; it makes sense that if a man is masculine - by virtue of a high score in ego orientation as well as gender differentiation he will tend to be innovative. However, when applied to a woman it appears to be self-contradictory. For a woman, having a high masculine index means that, although she may be ambitious and competitive (high ego orientation), she will not have a high inclination towards career in the first place (since she will also have high gender differentiation). In the words of Hofstede (1998):

"In masculine countries, both boys and girls learn to be ambitious and competitive, although the ambition of the girls may be directed toward the achievements of their brothers and later of their husbands and sons. They become cheerleaders...".

(Hofstede, 1998, p.84)

Could it be possible then that for women entrepreneurs, innovativeness is positively related with ego orientation but negatively with gender differentiation? If that were the case, for current purposes, one cannot use only ego orientation as the measure of masculinity and merely assume its positive correlation with gender differentiation. Neither can one combine the two constructs in a single masculinity dimension as adding the scores for the two constructs may result in their canceling each other out. Should the study proceed with masculinity as a single construct, the results are expected to yield a low inter-item correlation for that construct as well as other misleading conclusions.

Based on the above arguments, it becomes obvious that for the female population the theoretical link between masculinity and entrepreneurial innovativeness needs some reconsideration. It appears that the problem may be solved by splitting up the two factors - ego orientation and gender differentiation - and measuring each as a distinct construct 
on its own. Pursuant to this, the following hypotheses may be forwarded:

$\begin{aligned} \text { Hypothesis 1: } & \text { Gender differentiation is directly and } \\ & \text { negatively related to women's } \\ & \text { entrepreneurial innovativeness. }\end{aligned}$

Hypothesis 2: Ego orientation is directly and positively related to women's entrepreneurial innovativeness.

Furthermore, as highlighted in the literature review, differences in values between Malays and Chinese form the basis of the following hypotheses:

Hypothesis 3: Gender differentiation is higher among
Chinese women entrepreneurs than Malay
women entrepreneurs.

Hypothesis 4: Ego orientation is higher among Chinese women entrepreneurs than Malay women entrepreneurs.

Because gender differentiation refers to society's perception of what functions men and women should ideally serve, it may have an impact on the society's reaction to those who perform as expected and those who do not. In gender-differentiating cultures negative reactions to women managers manifest themselves in the form of a "glass ceiling" which refers to the barriers to career development experienced by many women which are not faced by their male counterparts. These include family and child care responsibilities, discrimination, male networks and organizational structures (Davidson \& Cooper, 1992). In entrepreneurship, women have found it more difficult than men to obtain loans and information to start a business, as well as earn respect from the society (Gundry et al., 2002).

Thus gender differentiation appears to be more than just a mediator between ethnicity and entrepreneurial innovativeness. Rather it is also an antecedent of another factor which in turn affects innovativeness. To capture all related elements which influence women's involvement and development in business, such as social reaction, glass ceilings and special assistance, the general concept of environmental support is used to represent the said factor. According to liberal feminists, a more supportive environment will result in enhanced performance by women entrepreneurs (DeTienne \& Chandler, 2007). Hence it is expected that:

Hypothesis 5: Gender differentiation is negatively and directly related to environmental support.

Hypothesis 6: Environmental support is positively and directly related to entrepreneurial innovativeness.

By extension of Hypotheses 5 and 6, it seems likely that the effect of gender differentiation on entrepreneurial innovativeness is mediated by environmental support. More importantly, the effect of ethnicity on entrepreneurial innovativeness is mediated by gender differentiation, ego orientation, and environmental support. Hence the following:

Hypothesis 7: The effect of gender differentiation on entrepreneurial innovativeness is mediated by environmental support.

Hypothesis 8: The effect of ethnicity on entrepreneurial innovativeness is mediated by gender differentiation, ego orientation, and environmental support.

Although studies have suggested a relationship between ethnicity and innovativeness (Omar, 2003), predicting the direction of the relationship in this case is not easy. This is because, at this point, it is not known which of the three intervening variables has the highest predictive power. Some might posit the superiority of the Chinese based on the overall economic performance of the different ethnic groups in Malaysia as shown earlier. However, judging from the low level of female participation in Malaysian labor force, i.e. $36 \%$ of the total working population (Malaysia. Department of Statistics, 2008), the overall economic performance observed of any ethnic group in the country is probably more reflective of its men's. Hence to assume that Chinese women entrepreneurs are more innovative than their Malay counterparts would be premature. Accordingly, the study makes no attempt to predict the direction of the relationship between ethnicity and entrepreneurial innovativeness. Therefore, as the last hypothesis, the following is proposed:

Hypothesis 9: There is a difference between Malay and Chinese women entrepreneurs in terms of their entrepreneurial innovativeness.

\section{Research methodology}

The study opted for a quantitative method via a survey as it enables collection and analysis of large amounts of primary data at a low cost. Surveys have been popular in many previous studies on culture-innovation relationships (e.g. Daghfous, Petrof \& Pons, 1999; Mueller \& Thomas, 2000; Slowikowski \& Jarratt, 1997; Tansuhaj et al., 1991; Thatcher et al., 2003).

The process began with the formulation of a questionnaire which consisted four sections: Personal and Business Characteristics, Value Statements, Environmental Support and Entrepreneurial Innovativeness. The continuous scales used 5-point intervals, and statements measuring gender differentiation and ego orientation were adapted from Hofstede (1980; 1998). Items for entrepreneurial innovativeness were self-developed to reflect various types of innovation commonly observed among Malaysian businesses (Table 1). In general the items are consistent with the definition of innovation given in earlier studies (Schumpeter, 1934; Zaltman, Duncan \& Holbeck, 1973; Johannessen, Olsen \& Lumpkin, 2001) which may be summarized as follows: 
"The level of novelty implemented by an entrepreneur with regards to the products, services, processes, technologies, ideas or strategies in various functions of the business which may facilitate the realization of its objectives. The degree of novelty or newness is as perceived by the individual entrepreneur."

After judging for content validity and pre-testing, some minor modifications were made and the questionnaires were subsequently mailed to the study sample. The current study defined the sample as Malay and Chinese women who were business owners or shareholders actively involved in the operation and decision-making of the said business, and whose business was registered with the Small and Medium Industries Development Corporation (SMIDEC). This segment of the total business population was chosen as the majority of Malaysian women-owned enterprises fit into the category (Ong \& Sieh, 2003). After filtering out incomplete addresses and double entries, the sampling frame consisted of 1,021 units.

Data were then analyzed using the Statistical Package for Social Sciences software. The study used two major statistical techniques: one, factor analysis to determine support for the reconceptualization of masculinity, and two, path analysis to test the hypotheses. According to Pedhazur (1997) path analysis is a straightforward extension of multiple regression which enables the investigation of both direct and indirect relationships among the variables. Thus results of the path analysis indicated the effect of ethnicity, ego orientation and gender differentiation on women's entrepreneurial innovativeness.

Table 1: Items measuring entrepreneurial innovativeness

\begin{tabular}{l|l}
\hline \multicolumn{1}{c|}{ Item } & Scale \\
\hline 1. Introduce new products or services within the same industry. \\
2. Engage new suppliers. \\
3. Promote existing products or services to new target markets. \\
4. Develop new uses for existing products or services. \\
5. Move to a new location. \\
6. Improve the quality of existing products or services. \\
7. Use new technology or machinery. \\
8. Open new branches. \\
9. Use new raw materials or supplies. \\
10. Change leadership or communtem; implemented; \\
11. Change the appearance or packaging of existing products or services. \\
12. Change business operating hours. \\
13. Restructure departments or functions in the organization. \\
14. Change the price of existing products or services. \\
15. Develop new promotional techniques.
\end{tabular}

\section{Results}

A total of 145 completed questionnaires were returned, which yielded a response rate of $14.2 \%$. After checking for gross incompleteness and physical defects, there were 138 usable responses.

\section{Profile of respondents}

Out of the total 138 respondents, $55 \%$ were Malay and the rest Chinese. A majority of them were in their 30s, were married and had children, and had received upper secondary schooling. Most were sole proprietors of firms offering consumer services, and had been operating for less than 5 years. The businesses were mostly located in the city, earned less than RM200,000 per annum, and had fewer than 5 employees.

\section{Discriminant validity}

Factor analysis was conducted on the 14 items of ego orientation (8 items) and gender differentiation (6 items) to see whether it was appropriate to conceptualize ego orientation and gender differentiation separately. The procedure resulted in the extraction of two factors (Table 2). Each of the 14 items had a loading of at least 0,5 in one of the components and none of them cross-loaded onto the other factor, indicating a clear-cut separation of constructs. Furthermore, all 8 items for ego orientation loaded onto Component 1 and all 6 items for gender differentiation loaded onto Component 2. This provided evidence that, for the current sample, the decision to examine gender differentiation and ego orientation separately was apt. 
Table 2: Rotated component matrix for the gender differentiation-ego orientation scale

\begin{tabular}{|c|c|c|}
\hline \multirow{2}{*}{ Item } & \multicolumn{2}{|c|}{ Component } \\
\hline & 1 & 2 \\
\hline $\begin{array}{l}\text { 1. Developing the economy is more important than protecting nature. } \\
\text { 2. A large organization is better than a small one. } \\
\text { 3. Work to live, not live to work (negatively-worded). } \\
\text { 4. The primary objective of a business entity should be profit-maximization. } \\
\text { 5. Organizational conflicts should be resolved through negotiation instead of force (negatively-worded). } \\
\text { 6. For the sake of the business, it is okay to uproot the family. } \\
\text { 7. Crimes may be reduced more through educational programs than stricter laws (negatively-worded). } \\
\text { 8. Violence on TV is acceptable. } \\
\text { 9. The main provider for a family should be the husband, not the wife. } \\
\text { 10. Both sons and daughters should help out with household chores (negatively-worded). } \\
\text { 11. It is okay for a man to make sexual advances towards a woman, but not vice versa. } \\
\text { 12. Certain professions are suitable only for men while some only for women. } \\
\text { 13. Boys and girls should attend the same subjects at school (negatively-worded). } \\
\text { 14. Men should be aggressive; women submissive. }\end{array}$ & $\begin{array}{l}\mathbf{0 , 7 3 6} \\
\mathbf{0 , 5 7 9} \\
\mathbf{0 , 7 3 7} \\
\mathbf{0 , 7 5 7} \\
\mathbf{0 , 7 7 7} \\
\mathbf{0 , 6 8 4} \\
\mathbf{0 , 8 7 0} \\
\mathbf{0 , 5 8 8} \\
0,140 \\
0,074 \\
0,113 \\
0,056 \\
0,154 \\
0,175\end{array}$ & $\begin{array}{c}0,136 \\
0,051 \\
0,135 \\
0,284 \\
-0,019 \\
0,169 \\
0,036 \\
0,151 \\
\mathbf{0 , 8 0 0} \\
\mathbf{0 , 7 6 6} \\
\mathbf{0 , 7 3 6} \\
\mathbf{0 , 7 9 2} \\
\mathbf{0 , 7 9 2} \\
\mathbf{0 , 7 3 6}\end{array}$ \\
\hline
\end{tabular}

\section{Path analysis and hypotheses testing}

Figure 1 summarizes the results of the multiple regressions on the full-effects model. Two paths, i.e. ethnicityinnovativeness and ego orientation-innovativeness, were found to be non-significant at $95 \%$ confidence level and thus eliminated. The trimmed model was derived and further tested through a second series of multiple regression. The results of the regression analysis on the trimmed model are presented in Figure 2. Based on the trimmed model, the indirect effects of ethnicity and gender differentiation on entrepreneurial innovativeness were calculated, as shown in Table 3. The two series of multiple regressions conducted have made it possible to calculate the total effects of ethnicity and gender differentiation on entrepreneurial innovativeness. Table 4 illustrates these effects.

In the path analysis, regression on the full-effects model showed that the direct effect of gender differentiation on entrepreneurial innovativeness is significant at the $95 \%$ confidence level. For the trimmed model, the effect remains significant (beta value -0,272). Therefore, Hypothesis $\mathbf{1}$ is supported. However results indicated that the effect of ego orientation is not significant and it is subsequently eliminated from subsequent analysis. Thus, Hypothesis 2 is not supported.
Mean difference in ego orientation between the two ethnic groups is significant $(\mathrm{p}=0,004)$ where the score was lower for Malays $(15,6316)$ than Chinese $(18,5484)$. Thus ethnicity appears to predict ego orientation $(p=0,004)$ although its ability to predict the change in the variable is very low $(\mathrm{R}$-square $=0,058)$. The direction of association was found to be as expected. Therefore, there is basis to support Hypothesis 3. There was a significant mean difference in gender differentiation between the two samples $(\mathrm{p}=0,000)$ and with the Chinese scoring higher than the Malays $(18,7258$ as compared to 12,7105$)$. Path analysis thus indicated that ethnicity is a significant predictor of gender differentiation $(p=0,000)$, predicting roughly $26 \%$ of the variability. The direction of the association was as expected. Hypothesis 4 is thus supported.

Path analysis results showed that gender differentiation is a significant predictor of environmental support (at the $95 \%$ confidence level) with beta value $-0,308$. Therefore there is support for Hypothesis 5. Results indicated that environmental support is a significant predictor of entrepreneurial innovativeness and that the direction is positive. Therefore, Hypothesis 6 is supported. However, the beta value $(0,234)$ implies that environmental support is a weaker predictor of innovativeness than gender differentiation. 
$-0.297$

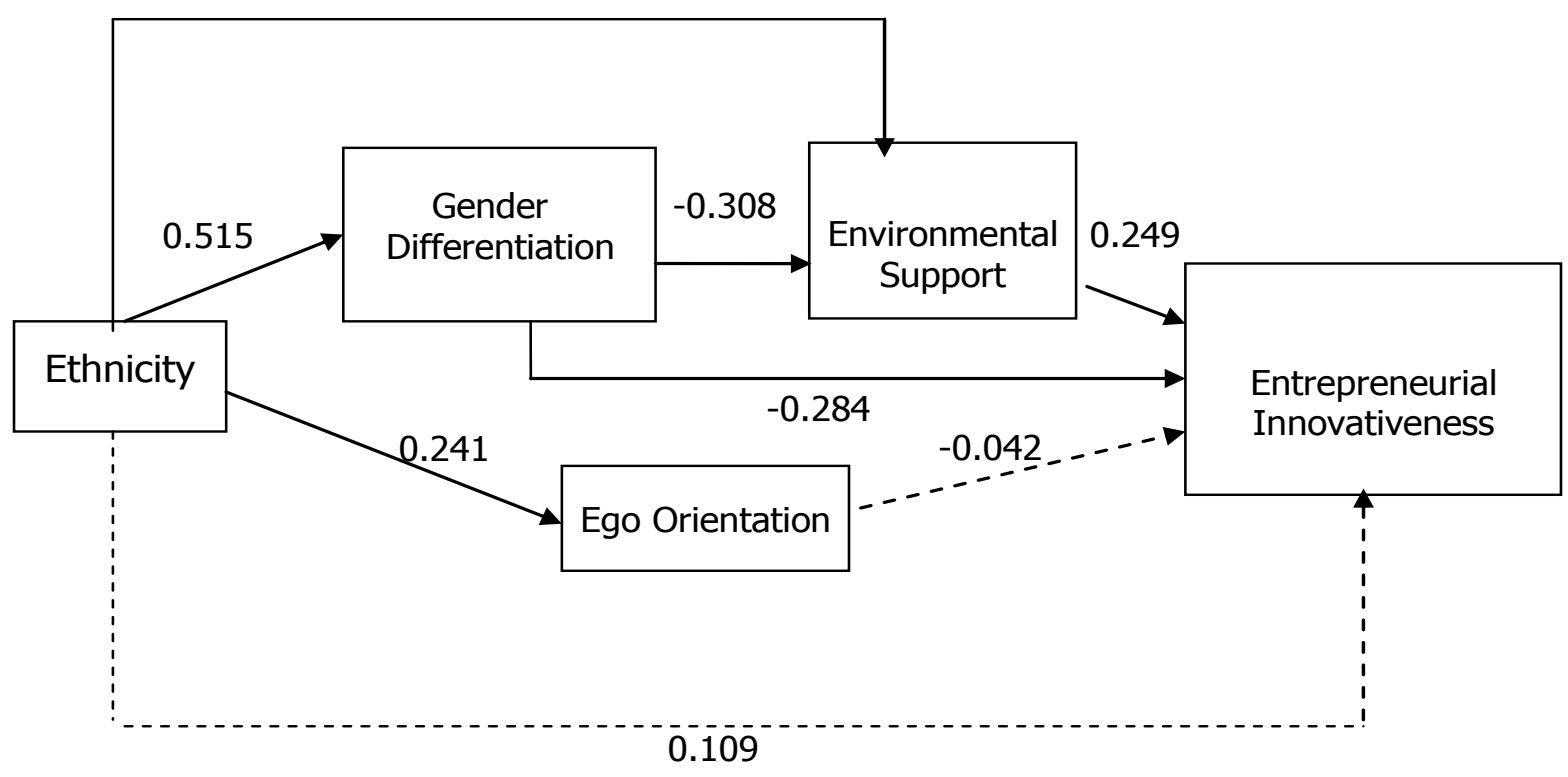

Note: Solid lines represent significant paths and dotted lines represent non-significant paths at $95 \%$ confidence level.

Figure 1: Multiple regressions on the full-effects model

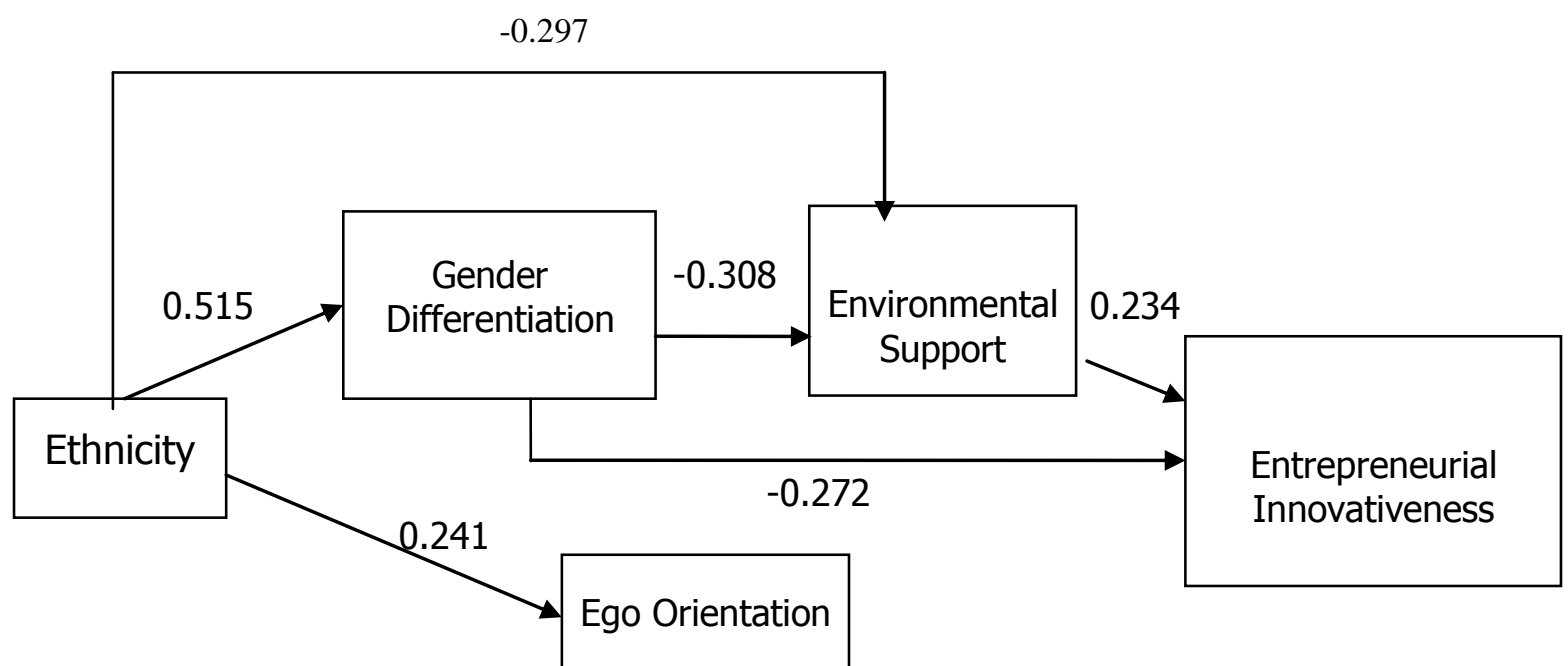

Figure 2: Multiple regressions on the trimmed model

Table 3: Indirect effects of ethnicity and gender differentiation on entrepreneurial innovativeness

\begin{tabular}{c|l|l|c}
\hline \multicolumn{1}{c|}{ Variables } & \multicolumn{1}{|c|}{ Indirect Paths } & \multicolumn{1}{|c}{ Path Coefficients } & Indirect Effects \\
\hline Ethnicity - Entrep. Innov. & Ethnicity-Gen Diff-Innov & $0,515 \times-0,272=-0,1401$ & $-0,1401+$ \\
& Ethnicity-Env Supp-Innov & $-0,297 \times 0,234=-0,0695$ & $-0,0695+$ \\
& Ethnicity-Gen Diff-Env Supp-Innov & $0,515 \times-0,308 \times 0,234=-0,0371$ & $-0,0371$ \\
& & & $-\mathbf{0 , 2 4 7 1}$ \\
\hline Gender Diff.-Entrep. Innov. & Gen Diff-Env Supp-Innov & $-0,308 \times 0,234=-0,0721$ & $\mathbf{- 0 , 0 7 2 1}$ \\
\hline
\end{tabular}


Table 4: Total effects of Ethnicity and gender differentiation on entrepreneurial innovativeness

\begin{tabular}{c|c|c|c}
\hline Variables & Indirect effects & Direct effect & Total effects \\
\hline $\begin{array}{c}\text { Ethnicity - } \\
\text { Entrepreneurial Innovativeness } \\
\begin{array}{c}\text { Gender Differentiation- } \\
\text { Entrepreneurial Innovativeness }\end{array}\end{array}$ & $-0,2471$ & Non-significant & $\mathbf{- 0 , 2 4 7 1}$ \\
\hline
\end{tabular}

In the path analysis, regression on the trimmed model enabled the indirect effect of gender differentiation on entrepreneurial innovativeness to be calculated. The results show that the value of this effect, which is transmitted through environmental support, is $-0,0721$. The direct effect, as indicated earlier, is $-0,284$. Adding the two yields a total effect of $-0,3561$. Thus it may be said that the inclusion of environmental support in the model has strengthened the effect of gender differentiation on entrepreneurial innovativeness. Based on these figures, Hypothesis 7 is supported.

Regression on the full-effects model showed that the direct effect of ethnicity on entrepreneurial innovativeness $(\mathrm{p}>0,05)$ is not significant. Therefore the total effect (0,2471 ) is made up entirely of the indirect components which are mediated through gender differentiation and environmental support. The path relating ego orientation and entrepreneurial innovativeness is not significant; hence ego orientation cannot be said to mediate the effect of ethnicity on entrepreneurial innovativeness. This provides partial support for Hypothesis 8.

The difference in means of entrepreneurial innovativeness between the Malay and Chinese samples was found to be significant at the 0,01 level. No direction was predicted for this relationship. However, the mean scores (i.e. Malay = 50,7763 and Chinese $=41,3226$ ) suggest that entrepreneurial innovativeness is higher among the Malays than the Chinese. Recall that gender differentiation is lower among the former and negatively related with entrepreneurial innovativeness. This may explain why the Malays have a higher score of entrepreneurial innovativeness than the Chinese. Hypothesis 9 is therefore supported.

\section{Discussion}

The first objective of the study was to determine the existence and extent of cultural differences between Malay and Chinese women entrepreneurs. Based on a literature review, a theoretical framework was proposed which posited that the Malay and Chinese samples differ in gender differentiation and ego orientation. An additional variable was also added to the framework, i.e. environmental support, which was suggested as a consequence of gender differentiation.

The research findings indicated that significant differences between the two groups exist in both value dimensions, as well as environmental support. Compared to the Chinese, the Malays are associated with lower gender differentiation and ego orientation, and higher environmental support. Innovation among Malay and Chinese women entrepreneurs was also examined. Results suggested that Malay women entrepreneurs may be more innovative than their Chinese counterparts. The study also investigated whether cultural values mediated the relationship between ethnicity and entrepreneurial innovativeness. Path analysis showed that gender differentiation is a significant mediator but ego orientation is not. In addition, environmental support was also found to have a mediating effect on this relationship. Thus, the difference in entrepreneurial innovativeness between Malay and Chinese women entrepreneurs appears to be a result of the differences in gender differentiation in their respective communities, and the level of environmental support they receive.

In the study, a series of hypotheses was tested through path analysis. The results of Hypothesis 2 did not conform to expectation. The analysis demonstrated that ego orientation is unable to significantly predict any variation in innovativeness. Worthier of mention is the direction of the association which was found to be negative. Contrary to some earlier findings (Shane, 1993), in this study, higher ego orientation appeared to be linked with lower innovativeness. A possible explanation for this is offered by Yeniyurt and Townsend (2003) who find that the direction of the association between ego orientation and innovativeness is found to be moderated by Gross Domestic Product (GDP). To be specific, in countries where the GDP is high, the sign is negative; where the GDP is low, it is positive. Although moderating factors are beyond the scope of this study, the issue certainly deserves due attention in future research.

\section{Conclusion}

The findings indicate the value of a female perspective in achieving a greater understanding of culture, entrepreneurship and innovation. The study suggests that although existing theories partially explain women's innovative behavior, they do not sufficiently highlight the issues women typically face in their business environment. This is apparent for example in how the study suggests that masculinity should be reconceptualized. While Hofstede (1980) contends that gender role differentiation and ego orientation are implicit constructs of masculinity, this study finds that for a female sample, the two constructs need to be measured explicitly and separately. Indeed only one of the two related constructs of masculinity, i.e. gender 
differentiation, was found to be a significant predictor of entrepreneurial innovativeness.

The emergence of gender differentiation as a construct separate from ego orientation has several implications for both cross-cultural and gender-related studies. First, it shows that a society's perception of women as well as her social role and status strongly affects her innovative capacity as an entrepreneur. Whether it has the same effect on men is something worth investigating. Also, gender differentiation has led to the addition of another variable to the framework, i.e. environmental support, which further influences women's entrepreneurial innovativeness.

In the study, social values have been shown to have a substantial impact on the innovativeness of women entrepreneurs. Thus if women are to have a better chance at improving their rate of innovation, cultivating the "right" values within the society is a challenge which community leaders need to take seriously. For instance, in Chinese family enterprises, children normally help out after school and start learning the tricks-of-the-trade from an early age. Unfortunately, sons are usually given greater exposure to entrepreneurial skills while daughters perform more mundane tasks. Hence despite their rich heritage in the family business culture, Chinese women are not able to benefit from informal training as much as Chinese men.

From the political viewpoint, perhaps the most gratifying finding of the study is that ethnicity has no direct effect on the women's innovativeness. Simply put, one is good at business not because one is Malay or Chinese but most likely because of one's skills and talents. In a pluralistic society such as Malaysia, the finding is celebrated particularly for its many positive consequences to nationbuilding. It can help reduce racism in the economic circle as it underlines the business potential of any Malaysian, regardless of creed and color. If no specific ethic group is associated with business superiority, there should be less risk that only that group is given priority in terms of financing, project awards, etc. Simultaneously, increased cooperation among the various communities is expected as they accord one another equal respect and recognition. The above understanding should also bring hope to budding entrepreneurs because values, unlike ethnicity, are changeable. Especially for the Malays who have long been associated with economic backwardness, it promises a way forward, provided they are willing to adopt a more positive mindset.

\section{References}

Abdul Rashid, M.Z. 1992. 'Management practices, motivations and problems of male and female entrepreneurs in Malaysia', Malaysian Journal of Small and Medium Enterprises, 3:35-46.

Abdullah, A. 1992. Understanding the Malaysian workforce. Kuala Lumpur: Malaysian Institute of Management.
Abdullah, A. 1996. Going glocal: Cultural dimensions in Malaysian management. Kuala Lumpur: Malaysian Institute of Management.

Al-Buraey, M.A. 1990. Management and administration in Islam. Dhahran: King Fahd University of Petroleum \& Minerals.

Ariffin, J. 1994. Readings on women and development in Malaysia. Kuala Lumpur: University of Malaya.

Bruni, A., Gherardi, S. \& Poggio, B. 2004. 'Doing gender, doing entrepreneurship', Gender, Work and Organization, 11(4): 406-429.

Brush, C. 2006. 'Women entrepreneurs: a research overview'. In Casson, M. Yeung, B. Basu, A. \& Wadeson, N. (eds.), The Oxford handbook of entrepreneurship, p.p.611-628. Oxford: Oxford University Press.

Chee, P. L. 1986. Small industry in Malaysia. Kuala Lumpur: Berita Publishing.

Daghfous, N., Petrof, J.V. \& Pons, F. 1999. 'Values and adoption of innovations', Journal of Consumer Marketing, 16(4):314-331.

Damanpour, F., Szabat, K.A. \& Evan, W.M. 1989. The relationship between types of innovation and organizational performance', Journal of Management Studies, 26(6):587601.

Davidson, M. J. \& Cooper, C. L. 1992. Shattering the glass ceiling: The woman manager. London: Paul Chapman.

De Bruin, A., Brush, C.G. \& Welter, F. 2007. 'Advancing a framework for coherent research on women's entrepreneurship', Entrepreneurship Theory and Practice, May: 323-339.

DeTienne, D.R. \& Chandler, G.N. 2007. 'The role of gender in opportunity identification', Entrepreneurship Theory and Practice, May: 365-386.

Din, H. 1999. Manusia dan Islam. Bangi: Haron Din.

Gundry, L.K., Ben-Yoseph, M. \& Posig, M. 2002. 'Contemporary perspectives on women's entrepreneurship: A review and strategic recommendations', Journal of Enterprising Culture, 10(1):67-86.

Hisrich, R.D. \& Ozturk, S.A. 1999. 'Women entrepreneurs in a developing economy', Journal of Management Development, 18(2):114-125.

Hofstede, G. 1980. Culture's consequences: International differences in work-related values. London: Sage.

Hofstede, G. (ed.) 1998. Masculinity and femininity: The taboo dimension of national cultures. Thousand Oaks: Sage. 
Idris, A. 2009. 'Management styles and innovation in women-owned enterprises', African Journal of Business Management, 3(9):416-425.

Inman, K. 2000. Women's resources in business start-up: A study of black and white women entrepreneurs. New York: Garland Publishing.

Ismail, M. \& Ibrahim, M. 2008. 'Barriers to career progression faced by women: Evidence from a Malaysian multinational oil company', Gender in Management, 23(1):51-66.

Ismail, M. \& Joned, R. 1999. 'The profile and value system of women entrepreneurs'. In Ahmad, A. Women and work: Challenges in industrializing nations. London: ASEAN Academic Press.

Johannessen, J-A., Olsen, B. \& Lumpkin, G.T. 2001. 'Innovation as newness: What is new, how new and new to whom?' European Journal of Innovation Management, 4(1):20-31.

Karim, W. J. (ed.) 1990. Emotions of culture: A Malay perspective. Singapore: Oxford University Press.

Kuah-Pearce, K.E. 2003. State, society and religious engineering. Singapore: Eastern Universities Press.

Lang, C.Y. \& Sieh, L.M.L. 1994. 'Women in business: Corporate managers and entrepreneurs'. In Jamilah Ariffin (ed.). Readings on women and development in Malaysia. Kuala Lumpur: Population Studies Unit, University of Malaya.

Lrong, Y. L. 1998. 'Cultural attributes of Malays and Malaysian Chinese: Implications for research and practice', Malaysian Management Review, 33(2):81-88.

Malaysia Department of Statistics. 2008a. Vital Statistics Time Series, Malaysia. Putrajaya: Department of Statistics.

Malaysia Department of Statistics. 2008b. Labour Force Survey Report. Putrajaya: Department of Statistics.

Malaysia Economic Planning Unit. 2005. Ninth Malaysia Plan. Putrajaya: Economic Planning Unit.

Malaysia Economic Planning Unit. 2000. Eighth Malaysia Plan. Putrajaya: Economic Planning Unit.

Maniam, M. 1986. 'The influence of culture in management in Malaysia', Malaysian Management Review, 21(3):3-7.

Mohamad, M. 1981. The Malay dilemma. Kuala Lumpur: Federal.

Mueller, S.L. \& Thomas, A.S. 2000. 'Culture and entrepreneurial potential: A nine country study of locus of control and innovativeness', Journal of Business Venturing, 16:51-75.
Ndubisi, O.N. \& Kahraman, C. 2005. 'Malaysian women entrepreneurs: Understanding the ICT usage behaviors and drivers', Journal of Enterprise Information Management, 18(6):721-739.

Neely, A., Filippini, R., Forza, C., Vinelli, A. \& Hii, J. 2001. 'A framework for analyzing business performance, firm innovation and related contextual factors: Perceptions of managers and policy makers in two European regions', Integrated Manufacturing Systems, 12(2):114-124.

Nonini, D.M. 1997. Small-scale Chinese businesses in Malaysia in an era of flexible capitalism. In Proceedings of the Chinese Business in Southeast Asia Conference, 23-25 June. Kuala Lumpur: University Malaya.

Olsson, S. 2000. 'Acknowledging the female archetype: Women managers' narratives of gender', Women in Management Review, 15(5/6):296-302.

Omar, S. 2003. The Malay lost world with emphasis on entrepreneurship. Shah Alam: Anzagain.

Ong, F.S. \& Sieh, L.M.L. 2003. 'Women Managers in the New Millenium: Growth strategies'. In Omar, R. \& Hamzah, A. (Eds.) Women in Malaysia breaking boundaries. Kuala Lumpur: Utusan.

Pan, F. \& Zhang, Z. 2003. 'Cross-cultural challenges when doing business in China', Singapore Management Review, 26(1):81-90.

Pedhazur, E.J. 1997. Multiple regression in behavioral research: Explanation and prediction. $3^{\text {rd }}$ Edition. Orlando: Holt, Rinehart and Winston.

Purcell, V. 1948. The Chinese in Malaysia. London: Oxford University Press.

Rigg, C. \& Sparrow, J. 1994. 'Gender, diversity and working styles', Women in Management Review, 9(1):9-16.

Schumpeter, J. A. 1934. The theory of economic development. Cambridge, MA: Harvard University Press.

Shane, S. 1992. 'Why do some societies invent more than others?' Journal of Business Venturing, 7: 29-46.

Shane, S. 1993. 'Cultural influences on national rates of innovation', Journal of Business Venturing, 8:59-73.

Sieh, L.M.L., Lang, C.Y., Phang, S. N. \& Norma Mansor 1991. Women managers of Malaysia. Kuala Lumpur: Faculty of Economics and Administration, University of Malaya.

Slowikowski, S. \& Jarratt, D.G. 1997. 'The impact of culture on the adoption of high technology products', Marketing Intelligence \& Planning, 15(2):97-105.

Smith-Hunter, A. \& Boyd, R.L. 2004. 'Comparative analysis of white and minority women business owners', Women in Management Review, 19(1):18-28. 
Syed Azizi W., Saufi, R.A. \& Chong K.F. 2003. 'Family ties, hard work, politics and their relationship with the career success of executives in local Chinese companies', Malaysian Management Review, 38(1):1-9.

Tansuhaj, P., Gentry, J.W., John, J., Manzer, L.L. \& Bong Jin Cho. 1991. 'A cross-national examination of innovation resistance', International Marketing Review, 8(3):7-20.

Thatcher, J.B., Srite, M., Stepina, L.P. \& Liu, Y. 2003. 'Culture, overload and personal innovativeness with information technology: Extending the nomological net', Journal of Computer Information Systems, Fall: 74-81.

Thomas, A.S. \& Mueller, S.L. 2000. 'A case for comparative entrepreneurship: Assessing the relevance of culture', Journal of International Business Studies, 31: 287301.

Watson, J. \& Newby, R. 2005. 'Biological sex, stereotypical sex-roles, and SME owner characteristics', International Journal of Entrepreneurial Behaviour and Research, 11(2):129-143.

Yeniyurt, S. \& Townsend, J.D. 2003. 'Does culture explain acceptance of new products in a country? An empirical investigation', International Marketing Review, 20(4):377396.

Yeung, H.W. 1997. 'The globalisation of ethnic Chinese business firms from Southeast Asia: Strategies, processes and competitive advantage.' In Proceedings of the Chinese Business in Southeast Asia Conference, 23-25 June. Kuala Lumpur: University Malaya.

Ying, F. 2000. 'A classification of Chinese culture', Crosscultural Management, 7(2):3-10.

Zaltman, G., Duncan, R. \& Holbeck, J. 1973. Innovations and organisations. New York: Wiley.

Zamani, A. 2002. The Malay ideals. Kuala Lumpur: Golden Books Centre.

Zhao, F. 2005. 'Exploring the synergy between entrepreneurship and innovation', International Journal of Behaviour and Research, 11(1):25-41. 